\title{
Seasonal influenza vaccine policies, recommendations and use in the World Health Organization's Western Pacific Region
}

\author{
Members of the Western Pacific Region Global Influenza Surveillance and Response System ${ }^{a}$ \\ Correspondence to Jeffrey Partridge (e-mail: PartridgeJ@vn.cdc.gov).
}

Objective: Vaccination is the most effective way to prevent seasonal influenza and its severe outcomes. The objective of our study was to synthesize information on seasonal influenza vaccination policies, recommendations and practices in place in 2011 for all countries and areas in the Western Pacific Region of the World Health Organization (WHO).

Methods: Data were collected via a questionnaire on seasonal influenza vaccination policies, recommendations and practices in place in 2011 .

Results: Thirty-six of the 37 countries and areas (97\%) responded to the survey. Eighteen (50\%) reported having established seasonal influenza vaccination policies, an additional seven (19\%) reported having recommendations for risk groups for seasonal influenza vaccination only and 11 (30\%) reported having no policies or recommendations in place. Of the 25 countries and areas with policies or recommendations, health-care workers and the elderly were most frequently recommended for vaccination; 24 (96\%) countries and areas recommended vaccinating these groups, followed by pregnant women (19 [76\%]), people with chronic illness (18 [72\%]) and children (15 [60\%]). Twenty-six (72\%) countries and areas reported having seasonal influenza vaccines available through public funding, private market purchase or both. Most of these countries and areas purchased only enough vaccine to cover $25 \%$ or less of their populations.

Discussion: In light of the new WHO position paper on influenza vaccines published in 2012 and the increasing availability of country-specific data, countries and areas should consider reviewing or developing their seasonal influenza vaccination policies to reduce morbidity and mortality associated with annual epidemics and as part of ongoing efforts for pandemic preparedness.

nfluenza is an acute viral infection transmitted person to person predominately through droplet spread. Worldwide, annual influenza epidemics result in about 3 to 5 million cases of severe illness and about 250000 to 500000 deaths. ${ }^{1}$ All age groups can be seriously affected, with the greatest risk of complications occurring among children aged under two years, adults 65 years or older, pregnant women and people of any age with certain chronic medical conditions or weakened immune systems. ${ }^{2}$ The most effective way to prevent seasonal influenza and its severe outcomes is through vaccination, and safe and effective vaccines have been used for more than 60 years. ${ }^{3}$ A recent systematic review of the scientific literature reported a pooled efficacy of 83\% (95\% confidence interval: 69\%-91\%) for trivalent live attenuated influenza vaccine in children six months to seven years of age. ${ }^{4}$ The same review reported that trivalent inactivated influenza vaccines had an efficacy of $59 \%$ (95\% confidence interval: $51 \%-67 \%$ ) in healthy adults 18-65 years of age and provided significant protection against medically attended influenza. There is also evidence demonstrating the socioeconomic benefits of vaccinating people against influenza. ${ }^{5-7}$

In the Western Pacific Region of the World Health Organization (WHO), awareness of the public health importance of influenza and the need for pandemic preparedness has increased in recent years motivated by the re-emergence of highly pathogenic avian influenza $A(H 5 N 1)$ in 2003-2004 and subsequently by the occurrence of the influenza $A(H 1 N 1)$ pandemic in 2009. The Region currently has three WHO Collaborating Centres for Reference and Research on Influenza and 21 National Influenza Centres in 15 countries that monitor the impact and evolution of influenza viruses and provide isolates for global vaccine strain selection and formulation. ${ }^{8,9}$ Despite the Western Pacific Region contributing more than $76 \%$ of the total virus isolates 
Figure 1. Countries and areas in WHO's Western Pacific Region*

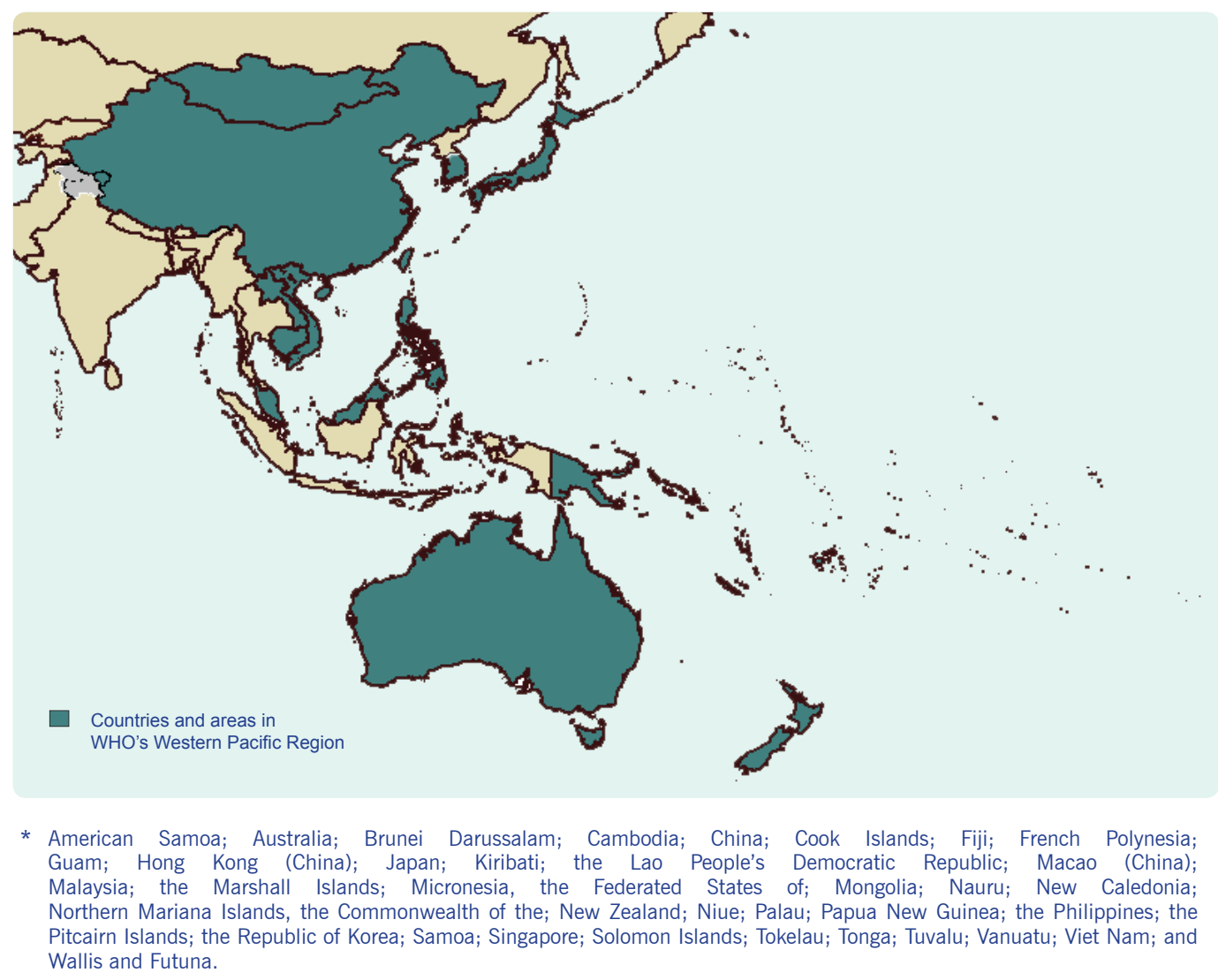

submitted to the WHO Global Influenza Surveillance Response and System (GISRS) between 1998 and 2010 for vaccine strain selection, ${ }^{10}$ influenza vaccination programmes have not been established consistently throughout the Region. These programmes facilitate governments' health policies for influenza vaccination and provide the mechanisms for ensuring the target groups for vaccination actually receive vaccines.

To describe seasonal influenza vaccination policies, recommendations and use in the Western Pacific Region, WHO conducted a survey in 2012. This report summarizes the results from the survey in the context of the new WHO position paper on vaccines against influenza that recommended pregnant women be given the highest priority for vaccination; it also recommended seasonal influenza vaccination for, in no order of priority, health-care workers, children aged six to 59 months, the elderly and persons with chronic medical conditions. ${ }^{11}$

\section{METHOD}

Data were collected via a survey conducted by WHO from July to October 2012. The questionnaire was sent electronically to all 37 countries and areas of WHO's
Western Pacific Region (Figure 1). ${ }^{12}$ Data collection was supported by regional members of GISRS, ${ }^{13}$ staff of the Expanded Programme on Immunization and WHO country or liaison offices. The questionnaire requested data and information on seasonal influenza vaccination policies, recommendations and practices in place in 2011, including: existence of a national vaccination policy; funding mechanisms for vaccines (public funding, private market purchase or both); recommendations for risk groups to target for vaccination; types of influenza vaccines available; number of vaccine doses purchased and distributed in 2011; the time period (months) when influenza vaccines were available for the 2011 southern hemisphere and the 2011-2012 northern hemisphere seasons; and the peak month(s) of influenza activity. Incomplete surveys were followed up until all information was provided. For one area that did not respond to the survey, data were extracted from the WHO 2010 Survey for the Global Mapping of Seasonal Influenza Vaccine (unpublished data). The proportion of the total population potentially covered with influenza vaccine was calculated using country and area population data from the WHO web site. ${ }^{12}$ Ethics review was not required for this study as it was a survey of policy and national-level practices, not a study involving individual human participants. 


\section{RESULTS}

Data were available from 36 (97\%) of the 37 countries and areas of the Western Pacific Region; 35 countries and areas responded to the questionnaire and one had responded to the WHO 2010 Survey for the Global Mapping of Seasonal Influenza Vaccine. Data were not available from the Commonwealth of the Northern Mariana Islands.

\section{Seasonal influenza vaccination policies}

Eighteen (50\%) countries and areas, comprising 93\% of the total population of the Western Pacific Region, reported having established seasonal influenza vaccination policies; an additional seven (19\%) reported providing influenza vaccination recommendations only for risk groups (but not as part of a vaccination policy). Eleven countries and areas (30\%) reported having no policy or recommendations in place. Of the 25 countries and areas with policy or recommendations, healthcare workers and the elderly were most frequently recommended for vaccination; 24 (96\%) countries and areas recommended vaccinating these groups, followed by pregnant women (19 [76\%]), people with chronic illness (18 [72\%]) and children (15 [60\%]). Other groups included in policies or recommendations were children only or the elderly with chronic illnesses, laboratory workers and first responders, caregivers of high-risk persons and Hajj pilgrims (Table 1).

\section{Seasonal influenza vaccine use}

Of the 36 participating countries and areas in the Region, 26 (72\%) reported that seasonal influenza vaccine was available through public funding, private market purchase or both (Table 2). Cambodia, Cook Islands, Singapore and Viet Nam reported that seasonal influenza vaccine was available through private market purchase only. The remaining 22 countries and areas reported that influenza vaccine was purchased by the government (seven countries and areas) or was available through both government and private market purchase (15 countries and areas). Ten (28\%) countries and areas reported that seasonal influenza vaccine was not available.

Of the 26 countries and areas with influenza vaccine available, seven $(27 \%)$ reported using only inactivated, non-adjuvanted, southern hemisphere formulation vaccine for the 2011 season. Five countries and areas (19\%) reported using both southern and northern hemisphere formulation vaccines, of which three used inactivated, non-adjuvanted vaccine and two used both non-adjuvanted and adjuvanted inactivated vaccines. The remaining 14 countries and areas (54\%) reported using northern hemisphere formulation vaccines, 12 of which used inactivated, non-adjuvanted vaccines. Palau reported using both inactivated, adjuvanted vaccine and live attenuated vaccine. Wallis and Futuna reported using inactivated, adjuvanted vaccine (Table 2).

For the 21 countries and areas that reported the number of doses of vaccine purchased, the estimated proportion of the total population that could be covered by the purchased amount ranged from $0.3 \%$ in Cook Islands to $99.7 \%$ in Tokelau. Most countries and areas purchased enough to cover less than $25 \%$ of their total populations. For the 17 countries and areas that reported the amount of vaccine distributed, the estimated proportion of the total population that could be covered again ranged from $0.3 \%$ in Cook Islands to $99.7 \%$ in Tokelau, with most estimates being less than 20\% (Table 2).

The majority of countries obtained their vaccine supply from international manufacturers. Australia, China and the Republic of Korea reported both domestic production and importation of influenza vaccines. Japan reported using only domestically produced vaccines (Table 2).

\section{Peak influenza seasons and vaccination timing}

Reported periods of peak influenza activity tended to coincide with the winter and spring months in temperate countries and areas and throughout the year in tropical countries and areas. For those countries and areas using southern hemisphere formulation vaccine, peak months of activity occurred from June to November, except for Macau (China) that reported having peak activity during February and March. Most countries and areas using the northern hemisphere formulation vaccine reported peak influenza months from December to April, although peaks before this period were reported by seven countries and areas, five in the Pacific. Those countries and areas that reported using both the southern and northern hemisphere formulation vaccines tended to report influenza activity throughout the year. Most countries and areas conducted their vaccination programmes in 
Table 1. Recommendations for vaccine recipients by country and area, WHO Western Pacific Region, 2011

\begin{tabular}{|c|c|c|c|c|c|c|c|}
\hline \multirow[b]{2}{*}{ Countrylarea } & \multirow[b]{2}{*}{ Policy } & \multicolumn{5}{|c|}{ Recommended recipients } & \multirow[b]{2}{*}{ Other risk groups and comments } \\
\hline & & HCW & $\begin{array}{l}\text { Elderly } \\
\text { (years) }\end{array}$ & $\begin{array}{l}\text { Chronic } \\
\text { illness }\end{array}$ & $\begin{array}{l}\text { Pregnant } \\
\text { women }\end{array}$ & $\begin{array}{l}\text { Children } \\
\text { (age) }\end{array}$ & \\
\hline American Samoa* & $\mathrm{N}$ & Y & $Y(>40)$ & Y & Y & $Y(6 m-18 y)$ & \\
\hline Australia & Y & Y & $Y(>65)$ & $\mathrm{N}$ & Y & $\mathrm{N}$ & $\begin{array}{l}\text { Aboriginal and Torres Strait Islanders older than } 15 \text { years, children } \\
\text { older than six months with pre-disposing conditions, residents } \\
\text { of nursing homes and other long-term care facilities, homeless } \\
\text { people and their caregivers, people who may transmit to those with } \\
\text { high risk of influenza complications, people in the poultry industry } \\
\text { during avian influenza activity, people providing essential services, } \\
\text { workers in other industries, travellers }\end{array}$ \\
\hline Brunei Darussalam & $\mathrm{Y}$ & Y & $Y(>60)$ & $\mathrm{N}$ & Y & $Y(6-23 y)$ & Hajj pilgrims \\
\hline Cambodia & $\mathrm{N}$ & - & - & - & - & - & \\
\hline China & Y & Y & $Y(>60)$ & $\mathrm{N}$ & Y & $Y(6-60 y)$ & $\begin{array}{l}\text { Close contacts of persons at high risk (staff of kindergartens and } \\
\text { nursery schools, household contacts and caregivers) }\end{array}$ \\
\hline Cook Islands* & $\mathrm{N}$ & Y & $Y(>60)$ & $\mathrm{N}$ & Y & $\mathrm{N}$ & \\
\hline Fiji & $\mathrm{N}$ & Y & Y & Y & $\mathrm{Y}$ & $\mathrm{N}$ & \\
\hline French Polynesia (France) & Y & Y & $Y(>60)$ & $\mathrm{Y}$ & Y & $\mathrm{N}$ & Persons with obesity (body mass index $>30$ ) \\
\hline Guam & Y & Y & $Y(\geq 50)$ & Y & Y & $Y(6 m-18 y)$ & $\begin{array}{l}\text { Adults aged } 19-49 \text { years with high-risk medical conditions (e.g. } \\
\text { asthma, heart conditions, lung conditions) } \\
\text { Note: Follow CDC recommendation for universal influenza vaccine } \\
\text { for any persons }\end{array}$ \\
\hline Hong Kong (China) & Y & Y & $Y(\geq 50)$ & Y & Y & $Y(6 \leq 71 y)$ & $\begin{array}{l}\text { Residents of nursing homes and long-term residents of homes for } \\
\text { the disabled; poultry workers, pig farmers and pig-slaughtering } \\
\text { industry personnel }\end{array}$ \\
\hline Japan & Y & $\mathrm{N}$ & $Y(>65)$ & $\mathrm{N}$ & $\mathrm{N}$ & $\mathrm{N}$ & \\
\hline Kiribati & $\mathrm{N}$ & - & - & - & - & - & \\
\hline Lao People's Democratic Republic & $\mathrm{N}$ & Y & $Y(>50)$ & Y & Y & Y & \\
\hline Macau (China) & Y & Y & $Y(>60)$ & Y & Y & $Y(6 m-18 y)$ & \\
\hline Malaysia & Y & Y & $\mathrm{N}$ & Y & $\mathrm{N}$ & $\mathrm{N}$ & Hajj pilgrims, elderly with one or more chronic illness \\
\hline Marshall Islands* & $\mathrm{N}$ & Y & Y & - & $\mathrm{Y}$ & Y & \\
\hline Micronesia, ${ }^{*}$ Federated States of & $\mathrm{N}$ & Y & $Y(<50)$ & Y & Y & $Y(6 m-18 y)$ & All adults over the age of 18 \\
\hline Mongolia & Y & Y & $Y(>60)$ & $\mathrm{N}$ & $\mathrm{N}$ & $\mathrm{N}$ & \\
\hline Nauru & $\mathrm{N}$ & - & - & - & - & - & \\
\hline New Caledonia & Y & Y & $Y(>65)$ & Y & $\mathrm{N}$ & $\mathrm{N}$ & Air and cruise crews \\
\hline New Zealand & Y & Y & $Y(>65)$ & Y & $\mathrm{Y}$ & $\mathrm{N}$ & $\begin{array}{l}\text { Persons of all ages with chronic conditions including children older } \\
\text { than six months with defined pre-disposing conditions }\end{array}$ \\
\hline Niue & Y & Y & $Y(>65)$ & Y & $\mathrm{N}$ & $\mathrm{N}$ & Children younger than six years with chronic illness \\
\hline $\begin{array}{l}\text { Northern Mariana Islands, } \\
\text { Commonwealth of the }\end{array}$ & $\mathrm{N}$ & - & - & - & - & - & \\
\hline $\mathrm{Palau}^{\dagger}$ & Y & Y & $\mathrm{Y}(>50)$ & Y & Y & $Y(\geq 6 y)$ & All first responders \\
\hline Papua New Guinea & $\mathrm{N}$ & - & - & - & - & - & \\
\hline Philippines & Y & Y & $Y(>60)$ & Y & $\mathrm{Y}$ & $Y(6 m-18 y)$ & $\begin{array}{l}\text { Healthy persons providing essential and emergency community } \\
\text { services, students and others in institutional settings } \\
\text { Public health policy is in place only for the targeting of } \\
\text { indigent elderly citizens. All other groups are public health } \\
\text { recommendations. }\end{array}$ \\
\hline Pitcairn Islands & $\mathrm{N}$ & - & - & - & - & - & \\
\hline Republic of Korea & $\mathrm{Y}$ & Y & $Y(>50)$ & Y & $\mathrm{Y}$ & $Y(6-60 y)$ & $\begin{array}{l}\text { Residents of nursing homes and other long-term care facilities, } \\
\text { caregivers of children younger than six months, infection control } \\
\text { personnel and workers in poultry-related industries. }\end{array}$ \\
\hline Samoa & $\mathrm{N}$ & - & - & - & - & - & \\
\hline Singapore & Y & Y & $Y(>65)$ & Y & Y & $Y(6-60 y)$ & $\begin{array}{l}\text { Children six months to } 18 \text { years on long-term aspirin therapy, } \\
\text { caregivers of children younger than } 6 \text { months, persons at high risk } \\
\text { of complications of influenza }\end{array}$ \\
\hline Solomon Islands & $\mathrm{N}$ & - & - & - & - & - & \\
\hline Tokelau & $\mathrm{N}$ & - & - & - & - & - & \\
\hline Tonga & $\mathrm{N}$ & - & - & - & - & - & \\
\hline Tuvalu & $\mathrm{N}$ & - & - & - & - & - & \\
\hline Vanuatu & $\mathrm{N}$ & - & - & - & - & - & \\
\hline Viet Nam & $\mathrm{N}$ & Y & $Y(>65)$ & Y & $\mathrm{N}$ & $Y(6-96 y)$ & \\
\hline Wallis and Futuna & $\mathrm{Y}$ & Y & $Y(>65)$ & Y & $\mathrm{Y}$ & $Y(6-60 y)$ & \\
\hline
\end{tabular}

CDC - Centers for Disease Control and Prevention; HCW - health-care workers; $\mathrm{m}$ - months; $\mathrm{N}$ - no; $\mathrm{y}$ - years; $\mathrm{Y}$ - Yes.

* These countries and areas reported not having established policy but having recommendations for seasonal influenza vaccination.

† Data from the WHO 2010 Global Influenza Vaccine Survey. 
Table 2. Vaccination information from countries and areas reporting having seasonal influenza vaccines available in 2011, WHO Western Pacific Region

\begin{tabular}{|c|c|c|c|c|c|c|c|c|c|}
\hline \multirow{2}{*}{$\begin{array}{c}\text { Countrylarea } \\
\text { American Samoa }\end{array}$} & \multirow{2}{*}{$\begin{array}{c}\begin{array}{c}\text { Year } \\
\text { vaccine } \\
\text { introduced }\end{array} \\
2003\end{array}$} & \multirow{2}{*}{$\begin{array}{c}\begin{array}{c}\text { Formu- } \\
\text { lation }\end{array} \\
\mathrm{NH}\end{array}$} & \multirow{2}{*}{$\begin{array}{c}\begin{array}{c}\text { Type of } \\
\text { vaccine }\end{array} \\
\text { TIV }\end{array}$} & \multirow{2}{*}{$\begin{array}{c}\begin{array}{c}\text { Public sector or } \\
\text { private market } \\
\text { purchase }\end{array} \\
\text { Both }\end{array}$} & \multicolumn{2}{|c|}{$\begin{array}{c}\text { No. doses } \\
\text { purchased } \\
\text { (\% of population) }\end{array}$} & \multicolumn{2}{|c|}{$\begin{array}{c}\text { No. doses } \\
\text { distributed } \\
\text { (\% of population) }\end{array}$} & \multirow{2}{*}{$\begin{array}{c}\begin{array}{c}\text { Source } \\
\text { (domestic or } \\
\text { international }\end{array} \\
\text { International }\end{array}$} \\
\hline & & & & & 8900 & $(12.1)$ & 6502 & $(11.5)$ & \\
\hline Australia & 1997 & $\mathrm{SH}$ & TIV & Both & 3776512 & $(16.9)$ & - & - & Both \\
\hline Brunei Darussalam & 2003 & Both & TIV & Both & 28000 & (6.9) & 26800 & (6.6) & International \\
\hline Cambodia & - & Both & TIV & Private & - & - & - & - & International \\
\hline China & 1998 & $\mathrm{NH}$ & TIV & Both & - & - & - & - & Both \\
\hline Cook Islands & 2010 & Both & TIV & Private & 60 & $(0.3)$ & 60 & $(0.3)$ & International \\
\hline French Polynesia & 2002 & $\mathrm{NH}$ & TIV & Both & 16000 & $(6.0)$ & - & - & International \\
\hline Guam & 1997 & $\mathrm{NH}$ & TIV & Public & 7300 & $(4.0)$ & - & - & International \\
\hline Hong Kong (China) & 1998 & $\mathrm{NH}$ & TIV & Both & 480000 & $(6.8)^{\ddagger}$ & 408000 & $(5.8)^{\ddagger}$ & International \\
\hline Japan & 1951 & $\mathrm{NH}$ & TIV & Both & 50000000 & $(39.2)$ & 50000000 & $(39.2)$ & Domestic \\
\hline Macau (China) & 2000 & $\mathrm{SH}$ & TIV & Both & 110000 & (19.9) & 85000 & $(15.4)$ & International \\
\hline Malaysia & 1988 & Both & TIV \& ATIV & Both $^{+}$ & - & - & - & - & International \\
\hline Marshall Islands & 2002 & $\mathrm{NH}$ & TIV & Public & 10000 & $(18.4)$ & 10000 & $(18.4)$ & International \\
\hline $\begin{array}{l}\text { Micronesia, } \\
\text { Federated States of }\end{array}$ & 2000 & $\mathrm{NH}$ & TIV & Public & 17000 & $(16.6)$ & 10000 & (9.3) & International \\
\hline Mongolia & 1979 & $\mathrm{NH}$ & TIV & Both & 17000 & $(0.6)$ & 17000 & $(0.6)$ & International \\
\hline New Caledonia & 1994 & $\mathrm{NH}$ & TIV & Both & 18460 & (7.5) & 18460 & (7.5) & International \\
\hline New Zealand & 1997 & $\mathrm{SH}$ & TIV & Both & 988000 & $(22.6)$ & 988000 & $(22.6)$ & International \\
\hline Niue & 2000 & $\mathrm{SH}$ & TIV & Public & 200 & $(13.4)$ & 200 & $(13.4)$ & International \\
\hline Palau* & 1996 & $\mathrm{NH}$ & TIV \& LAIV & Public & 5000 & $(24.3)$ & - & - & - \\
\hline Philippines & - & $\mathrm{SH}$ & TIV & Both & - & - & - & - & International \\
\hline Pitcairn Islands & 1997 & $\mathrm{SH}$ & TIV & Both & 30 & $(57.7)$ & 22 & $(42.3)$ & International \\
\hline Republic of Korea & 1997 & $\mathrm{NH}$ & TIV & Both & 3986900 & $(8.2)^{5}$ & 3986900 & $(8.2)^{5}$ & Both \\
\hline Singapore & 1988 & Both & TIV \& ATIV & Private & - & - & - & - & International \\
\hline Tokelau & 2009 & $\mathrm{SH}$ & TIV & Public & 1466 & $(99.7)$ & 1466 & $(99.7)$ & International \\
\hline Viet Nam & 2008 & $\mathrm{NH}$ & TIV & Private & - & - & - & - & International \\
\hline Wallis and Futuna & 2004 & $\mathrm{NH}$ & ATIV & Public & 1600 & (12.1) & 1530 & $(11.5)$ & International \\
\hline
\end{tabular}

ATIV - adjuvanted trivalent inactivated influenza vaccine; LAIV - live attenuated influenza vaccine; NH - northern hemisphere formulation; SH - southern hemisphere formulation; and TIV - trivalent inactivated influenza vaccine.

* Data from the WHO 2010 Global Influenza Vaccine Survey.

Public funding limited to frontline health-care workers.

¥ Estimation based on vaccine purchased by the government and claims made by private doctors to the government's Vaccine Subsidy Schemes.

$\$$ Public sector purchase figure, i.e. does not include the 9-10 million doses available through private market purchase.

the months before or during periods of peak influenza activity (Table 3).

\section{DISCUSSION}

Of the 36 countries and areas included in this study, 18 (50\%) reported having an established policy regarding seasonal influenza vaccination, which is a larger proportion than $40 \%$ of the 157 countries that reported having a policy in a global survey. ${ }^{14}$ Seven (19\%) additional countries and areas in the Western Pacific Region reported providing recommendations for risk groups for seasonal influenza vaccination, but these were not part of an established policy. However, unlike the rapid increase from 2004 in the number of countries in the Americas using seasonal influenza vaccine, ${ }^{15}$ only three (8\%) countries and areas in the Western Pacific Region reported introducing influenza vaccine after 2004. In 2011, influenza vaccine was not available in 10 (28\%) countries and areas, and influenza vaccine policy or recommendations were not available in $11(30 \%)$ countries and areas. Therefore, the increase in influenza surveillance and response capacity and pandemic preparedness in the Western Pacific Region in 
Table 3. Reported peak influenza month(s) and months of influenza vaccine availability, WHO Western Pacific Region, 2011

\begin{tabular}{|c|c|c|c|c|c|c|c|c|c|c|c|c|c|c|c|c|c|}
\hline \multirow{2}{*}{ Country } & \multirow{2}{*}{$\begin{array}{l}\text { Formu- } \\
\text { lation }\end{array}$} & \multicolumn{11}{|c|}{2011} & \multicolumn{5}{|c|}{2012} \\
\hline & & Feb & Mar & Apr & May & Jun & Jul & Aug & Sep & Oct & Nov & Dec & Jan & Feb & Mar & Apr & May \\
\hline American Samoa* & $\mathrm{NH}$ & & & & & & & & $v$ & & & & & & & & \\
\hline Australia & $\mathrm{SH}$ & & $v$ & $v$ & $v$ & $v$ & $v$ & v & v & v & & & & & & & \\
\hline Brunei Darussalam & Both & $v$ & v & $v$ & $v$ & $v$ & $v$ & $v$ & v & v & $v$ & $v$ & v & v & $v$ & v & $v$ \\
\hline Cambodia & Both & $v$ & v & $v$ & v & v & $v$ & v & v & v & v & v & v & v & $v$ & v & $v$ \\
\hline China & $\mathrm{NH}$ & & & & & & & v & v & v & $v$ & v & v & v & $v$ & & \\
\hline Cook Islands & Both & & & & v & v & & & & & & & & & & & \\
\hline Fiji & - & & & & & & & & & & & & & & & & \\
\hline French Polynesia & $\mathrm{NH}$ & & & & & & & & & v & $v$ & v & $v$ & & 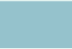 & & \\
\hline Guam & $\mathrm{NH}$ & $v$ & $v$ & $v$ & $v$ & v & & & v & $v$ & v & $v$ & v & v & $v$ & $v$ & $v$ \\
\hline Hong Kong (China) & $\mathrm{NH}$ & v & v & $v$ & $v$ & v & $v$ & $v$ & v & $v$ & v & $v$ & v & v & $v$ & v & $v$ \\
\hline Japan & $\mathrm{NH}$ & & & & & & & & & $v$ & v & $v$ & v & v & $v$ & v & \\
\hline Kiribati & - & & & & & & & & & & & & & & & & \\
\hline $\begin{array}{l}\text { Lao People's } \\
\text { Democratic Republic }\end{array}$ & - & & & & & & & & & & & & & & & & \\
\hline Macau (China) & $\mathrm{SH}$ & $v$ & v & $v$ & $v$ & v & & . & 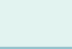 & v & v & v & & 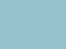 & 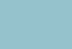 & & \\
\hline Malaysia & Both & v & v & v & v & v & v & v & v & $v$ & v & $v$ & v & v & v & v & $v$ \\
\hline Marshall Islands & $\mathrm{NH}$ & & & & & & & & & v & & & & & & & \\
\hline $\begin{array}{l}\text { Micronesia, } \\
\text { Federated States of }\end{array}$ & $\mathrm{NH}$ & & & & & & & & v & $v$ & $v$ & v & v & v & $v$ & $v$ & $v$ \\
\hline Mongolia & $\mathrm{NH}$ & & & & & & & & & $v$ & v & $v$ & v & & & & \\
\hline Nauru & - & & & & & & & & & & & & & & & & \\
\hline New Caledonia & $\mathrm{NH}$ & & & & & & & & & & v & $v$ & v & v & v & v & \\
\hline New Zealand & $\mathrm{SH}$ & & $v$ & $v$ & $v$ & v & v & & & & & & & & & & \\
\hline Niue & $\mathrm{SH}$ & & $v$ & $v$ & $v$ & v & v & v & v & & & & & & v & v & $v$ \\
\hline Palau $^{+}$ & $\mathrm{NH}$ & & & & & & & & & & & & & & & & \\
\hline Papua New Guinea & - & & & & & & & & & & & & & & & & \\
\hline Philippines & $\mathrm{SH}$ & & & & v & & & & & & & & & & & & \\
\hline Pitcairn Islands & $\mathrm{SH}$ & & & & & v & & & & & & & & & & & \\
\hline Republic of Korea ${ }^{\ddagger}$ & $\mathrm{NH}$ & & & & & & & v & v & $v$ & v & $v$ & $v$ & v & $v$ & & \\
\hline Samoa & - & & & & & & & & & & & & & & & & \\
\hline Singapore & Both & $v$ & v & $v$ & v & v & v & v & v & $v$ & v & v & v & v & $v$ & v & v \\
\hline Solomon Islands & - & & & & & & & & & & & & & & & & \\
\hline Tokelau* & $\mathrm{SH}$ & & & & & & & & & & & & & & & & \\
\hline Tonga & - & & & & & & & & & & & & & & & & \\
\hline Tuvalu & - & & & & & & & & & & & & & & & & \\
\hline Vanuatu & - & & & & & & & & & & & & & & & & \\
\hline Viet Nam & $\mathrm{NH}$ & & & & & & & & & & & & & & & & \\
\hline Wallis and Futuna & $\mathrm{NH}$ & & & & & & & & & & & & v & & & & \\
\hline
\end{tabular}

Key: Shaded months are the reported peak months for influenza illness; $v$ - vaccine available.

$\mathrm{NH}$ - northern hemisphere formulation; SH - southern hemisphere formulation; "-" - influenza vaccine currently not available.

* American Samoa and Tokelau reported unknown vaccination month(s).

† Data from the WHO 2010 Global Influenza Vaccine Survey - seasonality and vaccine availability not reported.

¥ Public sector-purchased vaccine available October-December.

recent years ${ }^{16}$ has not been consistent across the Region in the use of vaccines as an effective control measure. This is particularly true in Pacific island nations.
The 2012 WHO position paper on vaccines against influenza recommended that pregnant women be given the highest priority for vaccination in countries initiating or 
expanding seasonal influenza vaccination programmes. This recommendation was based on the risk of severe disease in this group, the evidence of the safety of trivalent inactivated influenza vaccines throughout pregnancy and the effectiveness of vaccines in preventing illness for the women and their infants. ${ }^{11}$ The vaccination of pregnant women has also been shown to be cost-effective in the United Kingdom and Northern Ireland. ${ }^{17}$ Although the proportion of countries and areas in the Western Pacific Region that have recommended pregnant women as a risk group for vaccination (76\%) is higher than the proportion reported from Europe (37\%), ${ }^{18}$ more work is needed to promote the inclusion of this risk group in existing and new policies and recommendations in the Region.

The new WHO position paper also recommended seasonal influenza vaccination for, in no order of priority, health-care workers, children aged six to 59 months, the elderly and persons with chronic medical conditions. All 18 countries and areas in the Region with public policies for seasonal influenza vaccination recommended vaccination for health-care workers and the elderly, which is consistent with reports from European countries $^{18}$ and the global vaccination survey. ${ }^{14}$ Children were included in 15 (60\%) country and area vaccination policies or recommendations in the Region, a much larger proportion than that reported by six $(22 \%)$ of 27 European countries. ${ }^{18}$ A global study comparing 10 countries in 2006 showed that the highest vaccination coverage rates for children were from the three Asian countries in the study, suggesting that paediatric vaccination is important in the Asia. ${ }^{19}$ Persons at high risk of complications from influenza and/or those with chronic medical conditions were recommended for influenza vaccination in the policies of 18 (72\%) countries and areas in the Region, higher than the proportions reported from European countries. ${ }^{18}$

Since 2006, there has been a global push to increase both the production and use of seasonal influenza vaccines through activities contained in the WHO Global Action Plan for Influenza Vaccines. ${ }^{20}$ As a result, the number of countries that produce seasonal influenza vaccine has increased both globally and in the Western Pacific Region. 14,21,22 In 2008, WHO awarded grants to manufacturers in three countries in the Region, namely China, the Republic of Korea and Viet Nam. The manufacturer in the Republic of Korea has since licensed both pandemic and trivalent seasonal vaccines; the other two manufacturers are at different stages of development. ${ }^{22}$ Despite the increase in vaccine production, this study shows the lack of concomitant vaccine use as most countries and areas that reported influenza vaccine use reported purchasing and/or using only enough vaccine to cover less than $25 \%$ of their total populations. Global seasonal influenza manufacturers reported that, despite growth in production capacity at the global, regional and national levels, more than two-thirds of countries distributed vaccine to cover only $10 \%$ of their populations. ${ }^{14}$ Unfortunately, as risk-group population data were not collected by this study, it was not determined whether the reported number of doses of vaccine purchased by countries and areas were sufficient to cover the high-risk groups identified in vaccination policies or recommendations.

The second WHO Global Action Plan for Influenza Vaccines will place more focus on increasing seasonal vaccine use. ${ }^{20}$ Reimbursement, communication, and, to a lesser extent, a country's development status have been previously correlated with vaccine use. ${ }^{14}$ In China, the experiences in Beijing and Shaanxi suggest that effective promotional campaigns with reimbursement policies increase uptake in both high- and low-income areas. ${ }^{23}$ Similarly, in a survey of 10 countries, higher rates of vaccination were generally observed in countries with existing recommendations or vaccination programmes. ${ }^{19}$

One component of a successful vaccination programme is a surveillance system that monitors the impact of vaccination on disease burden. The results from this study show that most countries and areas schedule their vaccination campaign before or during their peak influenza season, but they also show that several countries and areas reported peak seasons inconsistent with their current vaccination schedule. Given the progress made in influenza surveillance capacity development in the Western Pacific Region in recent years, countries and areas are better able to understand the epidemiology of influenza in their populations, including seasonal patterns, and can now better match vaccination programmes with influenza seasonality. ${ }^{24}$ In addition, to support policy and vaccination recommendations, GISRS members in the Region have developed a workplan to improve surveillance systems and to promote the implementation of special studies for additional data required. ${ }^{25}$

This study shows that more than two-thirds of the countries and areas in WHO's Western Pacific Region 
have either seasonal influenza vaccination policies or recommendations for vaccinating high-risk groups. In light of the new WHO position paper on vaccines against influenza published in 2012 and the increasing availability of country-specific data, countries and areas should consider reviewing or developing their seasonal influenza vaccination policies or recommendations to reduce morbidity and mortality associated with annual epidemics and as part of ongoing efforts for pandemic preparedness.

\section{Conflicts of interest}

As the Coordinating Editor of WPSAR was an author, another member of the Editorial team managed this publication.

\section{Funding}

None.

\section{Authors}

Members of the Western Pacific Region Global Influenza Surveillance and Response System, who served as contributing authors for this study, are as follows: Dominic Dwyer (Institute for Clinical Pathology and Medical Research, Australia); Ian Barr, Aeron Hurt, Anne Kelso, Patrick Reading and Sheena Sullivan (WHO Collaborating Centre for Reference and Research on Influenza, Victorian Infectious Diseases Reference Laboratory, Australia); Philippe Buchy (Institut Pasteur du Cambodge, Cambodia); Hongjie Yu and Jiandong Zheng (Chinese Center for Disease Control and Prevention); Yuelong Shu and Dayan Wang (Chinese National Influenza Center, Institute for Viral Disease Control and Prevention, China); Centre for Health Protection, Department of Health, Hong Kong (China), Dr Lam (Health Bureau, Macao [China]); Annette Aguon and Rita Q Oliva (Department of Public Health and Social Services, Guam); Takato Odagiri and Masato Tashiro (National Institute for Infectious Diseases, Japan); Khebir Verasahib (Ministry of Health, Malaysia); Mohd Apandi Yusof (Institute for Medical Research, Malaysia); Pagbajabyn Nymadawa and Burmaa Alexander (National Influenza Center, Mongolia); Anne-Claire Gourinat (Institut Pasteur de NouvelleCalédonie, New Caldedonia); Jean-Paul Grangeon (Gouvernement de la Nouvelle-Calédonie, New Caledonia); Lance Jennings (Canterbury
Health Laboratories, New Zealand); Sue Huang (Institute of Environmental Science and Research, New Zealand); Paul Horwood (Papua New Guinea Institute of Medical Research, Papua New Guinea); Marilla Lucero, Vito Roque Jr and Lyndon Lee Suy (Department of Health, the Philippines); Peter Cardon (Medical Officer, the Pitcairn Islands); Amado Tandoc III (Research Institute for Tropical Medicine, the Philippines); Remigio M Olveda (National Influenza Centre, Philippines); Chun Kang and Park Young-Joon (Republic of Korea Centers for Disease Control and Prevention); Jeffery Cutter, Raymond Lin and Constance Low (Ministry of Health, Singapore); Le Thi Quynh Mai (National Institute of Hygiene and Epidemiology, Viet Nam); Amanda Balish, James Kile, Shang Mei, Jeffrey Mcfarland, Ann Moen, Sonja Olsen, Gina Samaan and Xu Xiyan (Centers for Disease Control and Prevention, United States of America); and Nora Chea, Sergey Diorditsa, Keith Feldon, Kimberley Fox, Mendsaikhan Jamsran, Frank Konings, Hannah Catherine Lewis, Michelle McPherson, Eric Nilles, Babatunde Olowokure, Jeffrey Partridge (World Health Organization).

\section{References:}

1. Influenza (Seasonal). Fact sheet No. 211. Geneva, World Health Organization, 2012 (http://www.who.int/mediacentre/factsheets/ fs211/en/index.html, accessed 11 December 2012).

2. Wiselka M. Influenza: diagnosis, management, and prophylaxis. BMJ (Clinical Research Edition), 1994, 308:1341-1345. doi:10.1136/bmj.308.6940.1341 pmid:8019225

3. Hampson AW. Vaccines for pandemic influenza. The history of our current vaccines, their limitations and the requirements to deal with a pandemic threat. Annals of the Academy of Medicine, Singapore, 2008, 37:510-517. pmid:18618064

4. Osterholm MT et al. Efficacy and effectiveness of influenza vaccines: a systematic review and meta-analysis. The Lancet Infectious Diseases, 2012, 12:36-44. doi:10.1016/S14733099(11)70295-X pmid:22032844

5. Baguelin $\mathrm{M}$ et al. Health and economic impact of the seasonal influenza vaccination programme in England. Vaccine, 2012, 30:3459-3462. doi:10.1016/j.vaccine.2012.03.019 PMID:22446636

6. Postma MJ et al. Further evidence for favorable costeffectiveness of elderly influenza vaccination. Expert Review of Pharmacoeconomics \& Outcomes Research, 2006, 6:215227. doi:10.1586/14737167.6.2.215 pmid:20528557

7. Prosser LA et al. Health benefits, risks, and cost-effectiveness of influenza vaccination of children. Emerging Infectious Diseases, 2006, 12:1548-1558. doi:10.3201/eid1210.051015 pmid: 17176570

8. List of WHO Collaborating Centres for Reference and Research on Influenza. Geneva, World Health Organization, 2012 (http://www.who.int/influenza/gisrs_laboratory/collaborating_ centres/list/en/index.html, accessed 11 December 2012). 
9. List of National Influenza Centres of the Western Pacific Region. Manila, World Health Organization Regional Office for the Western Pacific, 2012 (http://www.wpro.who.int/topics/influenza/NIC.pdf, accessed 11 December 2012).

10. Oshitani H. Influenza surveillance and control in the Western Pacific Region. Western Pacific Surveillance and Response Journal, 2010, 1:3-4. doi:10.5365/wpsar.2010.1.1.005 pmid:23908873

11. World Health Organization. Vaccines against influenza WHO position paper - November 2012. Weekly Epidemiological Record, 2012, 87:461-476. pmid:23210147

12. Countries and areas. Manila, World Health Organization Regional Office for the Western Pacific, 2012 (http://www.wpro.who.int/ countries/en/, accessed 13 August 2012).

13. Sixth Meeting of National Influenza Centres and Influenza Surveillance in the Western Pacific and South-East Asia Regions. Manila, World Health Organization Regional Office for the Western Pacific, 2012 (http://www.wpro.who.int/ emerging_diseases/meetings/docs/6th.NIC.Meeting.Report.pdf, accessed 11 December 2012).

14. Palache A. Seasonal influenza vaccine provision in 157 countries (2004-2009) and the potential influence of national public health policies. Vaccine, 2011, 29:9459-9466. doi:10.1016/j. vaccine.2011.10.030 pmid:22024174

15. Ropero-Alvarez $A M$ et al. Expansion of seasonal influenza vaccination in the Americas. BMC Public Health, 2009, 9:361. doi:10.1186/1471-2458-9-361 pmid:19778430

16. World Health Organization. Fifth meeting of National Influenza Centres - WHO Western Pacific and South-East Asia Regions. Weekly Epidemiological Record, 2012, 87:61-64. pmid:22355834

17. Jit $M$ et al. The cost-effectiveness of vaccinating pregnant women against seasonal influenza in England and Wales. Vaccine, 2010, 29:115-122. doi:10.1016/j.vaccine.2010.08.078 pmid:21055501
18. Mereckiene $\mathrm{J}$ et al. Differences in national influenza vaccination policies across the European Union, Norway and Iceland 20082009. Euro Surveillance: European Communicable Disease Bulletin, 2010, 15(44):pii=19700.

19. de Lataillade C, Auvergne S, Delannoy I. 2005 and 2006 seasonal influenza vaccination coverage rates in 10 countries in Africa, Asia Pacific, Europe, Latin America and the Middle East. Journal of Public Health Policy, 2009, 30:83-101. doi:10.1057/ jphp.2008.40 pmid:19367303

20. Report of the second WHO Consultation on the Global Action Plan for Influenza Vaccines (GAP). Geneva, World Health Organization, 2011.

21. Partridge J, Kieny MP, World Health Organization H1N1 influenza vaccine Task Force. Global production of seasonal and pandemic (H1N1) influenza vaccines in 2009-2010 and comparison with previous estimates and global action plan targets. Vaccine, 2010, 28:4709-4712. doi:10.1016/j.vaccine.2010.04.083 pmid:20488262

22. Partridge J, Kieny MP. Global production capacity of seasonal influenza vaccine in 2011. Vaccine, 2013, 31:728-731. doi:10.1016/j.vaccine.2012.10.111 pmid:23149268

23. Feng $L$ et al. Seasonal influenza vaccine supply and target vaccinated population in China, 2004-2009. Vaccine, 2010, 28:6778-6782. doi:10.1016/j.vaccine.2010.07.064 pmid:20688038

24. Western Pacific Region Global Influenza Surveillance and Response System. Epidemiological and virological characteristics of influenza in the Western Pacific Region of the World Health Organization, 2006-2010. PLoS ONE, 2012, 7:e37568. doi:10.1371/journal. pone.0037568 pmid:22675427

25. Biregional Plan for Further Strengthening National Influenza Surveillance. Guiding the way towards Influenza Control Policy and Regional Surveillance. Manila, World Health Organization Regional Office for the Western Pacific, 2012 (http://www.wpro. who.int/topics/influenza/InfluenzaSurveillanceFiveYearWorkplan website.pdf., accessed 11 December 2012). 